\title{
Hydrocortisone Impairs Hippocampal-Dependent Trace Eyeblink Conditioning in Post-Traumatic Stress Disorder
}

\author{
Meena Vythilingam*,', Megan Lawley', Carlos Collin², Omer Bonne', Rajni Agarwal', Kayleen Hadd', \\ Dennis S Charney ${ }^{3}$ and Christian Grillon' \\ 'Mood and Anxiety Disorders Program, National Institute of Mental Health, Bethesda, MD, USA; ${ }^{2}$ Community Behavioral Health, Rockville, MD, \\ USA; ${ }^{3}$ Mount Sinai School of Medicine, New York, NY, USA
}

\begin{abstract}
Trace eyeblink conditioning is a hippocampal-dependent associative learning task that could help evaluate hippocampal function in Posttraumatic stress disorder (PTSD). Since preclinical research has demonstrated that trace eyeblink conditioning can be pharmacologically manipulated by glucocorticoids, this task may shed light on glucocorticoid sensitivity in PTSD. This study assessed baseline and hydrocortisone-mediated changes in trace eyeblink conditioning in patients with PTSD and in healthy controls. A total of 12 patients with PTSD and 12 age- and sex-matched healthy controls participated in a trace eyeblink test $6 \mathrm{~h}$ following intravenous administration of $30 \mathrm{mg}$ of hydrocortisone. Spontaneous blink rates were similar between PTSD patients and healthy controls. There was no significant difference in the mean conditioned response between PTSD subjects and healthy controls under placebo conditions. Following hydrocortisone administration, only the PTSD patients demonstrated a significant reduction in conditioned response in contrast to healthy subjects who did not demonstrate any change. Patients with PTSD had increased glucocorticoid sensitivity in the focal brain regions mediating trace eyeblink conditioning.

Neuropsychopharmacology (2006) 3 I, I82-188. doi: I0.1038/sj.npp. I 300843; published online 3 August 2005
\end{abstract}

Keywords: Post-traumatic stress disorder; trace eyeblink conditioning; glucocorticoid sensitivity; hippocampus

\section{INTRODUCTION}

Eyeblink conditioning is a simple form of associative learning that can easily be translated from preclinical studies to clinical populations and could help evaluate hippocampal function in post-traumatic stress disorder (PTSD). It has been studied extensively in animals (Christian and Thompson, 2003; Steinmetz et al, 2001) and is becoming an important tool in evaluating learning and memory in humans (Clark and Squire, 1998; Fortier et al, 2003; Marenco et al, 2003). One of the advantages of evaluating eyeblink conditioning in neuropsychiatric populations is that it requires little cooperation from the subjects. Relative to other learning and memory tasks, results are less likely to be affected by nonspecific factors such as motivation.

There are two different kinds of eyeblink conditioning: delayed eyeblink conditioning and trace eye blink conditioning. In delayed eyeblink conditioning, the conditioned stimulus (CS), a short duration (eg $400 \mathrm{~ms}$ ) tone, overlaps

*Correspondence: Dr M Vythilingam, NIH NIMH/MAP, I5K North Drive, Room \# III, MSC 2670, Bethesda, MD 20892-2670, USA, Tel: 30 I 594 1798, Fax: 301594 9959, E-mail: meena.vythi@nih.gov Received I September 2004; revised 15 April 2005; accepted 16 June 2005

Online publication: 22 June 2005 at http://www.acnp.org/citations/ Npp062205040400/default.pdf and coterminates with the unconditioned stimulus (US), a 100-ms duration weak air puff delivered to the cornea that induces an eyeblink unconditioned response (UR). Following repeated tone-air puff pairing, the CS is able to elicit an eyeblink before the occurrence of the air puff. The cerebellum mediates this form of implicit learning (Lavond et al, 1993). In trace eyeblink conditioning, an empty interval separates the end of the tone from the onset of the air puff. Trace eyeblink conditioning is an explicit learning task requiring awareness of CS-US relationship (Clark and Squire, 1998). Preclinical and emerging literature in humans suggest that trace eyeblink conditioning is dependent on both the cerebellum and the stress-sensitive hippocampal neurons in the CA1 and CA3 regions (Berger and Thompson, 1978; Clark and Squire, 1998; McEchron and Disterhoft, 1997; Moyer et al, 1990; Weiss et al, 1996).

Glucocorticoids play a critical role in modulating trace eyeblink conditioning since removal of both the adrenal cortex and medulla but not medulla alone prevents enhancement of trace eyeblink conditioning in male rats (Beylin et al, 2001; Beylin and Shors, 2003). Basal levels of glucocorticoids are also positively correlated with trace eyeblink conditioning (Wood et al, 2001). Very few studies have evaluated trace eyeblink conditioning in humans with abnormalities in baseline glucocorticoids levels. Subjects with hypercortisolemia due to Cushing's syndrome had fewer conditioned responses using a trace eyeblink con- 
ditioning paradigm compared to healthy subjects (Grillon et al, 2004). Although PTSD is a chronic anxiety disorder characterized by abnormalities in plasma and salivary cortisol levels, trace eyeblink conditioning has not been evaluated in this disorder. The only study that evaluated eyeblink conditioning in PTSD used a delayed paradigm and reported impairments in both combat veterans with and without PTSD (Ayers et al, 2003). The results from this study are difficult to interpret because the experimental condition (paired CS-air puff) elicited less conditioned response compared to the control condition (unpaired CS-air puff) (Ayers et al, 2003), when the opposite should be expected.

Trace eyeblink conditioning can also be pharmacologically manipulated similar to tasks evaluating learning and memory and is sensitive to the effects of glucocorticoids (Beylin and Shors, 2003). Since its neurobiological basis is fairly well understood, trace eyeblink conditioning is a unique tool that can be used to explore the effects of glucocorticoid administration and shed light on the status of central glucocorticoid receptor sensitivity in the brain.

PTSD has been associated with low plasma cortisol (Yehuda et al, 1996) and an increased sensitivity to glucocorticoids (Coupland et al, 2003; Goenjian et al, 1996; Gotovac et al, 2003; Rohleder et al, 2004; Stein et al, 1997b; Yehuda et al, 1995, 2004a). Changes in trace eyeblink conditioning following a pharmacological challenge with hydrocortisone could help evaluate glucocorticoid sensitivity of focal brain regions such as the hippocampus in PTSD.

This present study assessed baseline hippocampal function in PTSD by evaluating conditioned response to trace eyeblink conditioning. Changes in this psychophysiological paradigm following a stress dose of hydrocortisone were used to evaluate glucocorticoid sensitivity in PTSD. We hypothesized that subjects with PTSD will have decreased conditioned response to trace eyeblink conditioning under placebo conditions and that hydrocortisone would worsen this impairment.

\section{PATIENTS AND METHODS}

\section{Participants}

A total of 12 patients with PTSD and 12 age- and sexmatched healthy controls participated in the study. The participants were recruited from the Mood and Anxiety Disorder Program Clinic at the National Institute of Mental Health (NIMH). Subjects were also recruited through NIMH Institutional Review Board (IRB) approved fliers and advertisements placed in the local media. Healthy subjects were recruited from the pool of healthy subjects interested in participating in research at the NIMH available through the NIH. All the patients were free of medication for at least 2 weeks prior to testing.

Participants in the patient group had to meet the DSM-IV (1994) criteria for PTSD based on the Structural Clinical Interview for DSM-IV Axis I disorder (SCID) (First et al, 1997). Subjects with PTSD were included if the severity of the PTSD as measured by the Clinician Administered PTSD Scale (CAPS) (Blake et al, 1995, 1990) was $>50$. All subjects were screened for trauma exposure using the Life Events Checklist (Blake et al, 1990), Early Trauma Inventory
(Bremner et al, 2000), and the SCID IV. Healthy controls did not have a current history of psychiatric illnesses according to the SCID. All eligible subjects were in good physical health as confirmed by a complete physical exam (including normal vital signs), electrocardiogram, neurological exam, and routine laboratory tests of blood and urine. All participants gave written informed consent for participation in the study. The consent forms were also approved by the NIMH IRB.

\section{Design}

Intravenous hydrocortisone $(30 \mathrm{mgs}$ ) or placebo (normal saline) was administered as a bolus a week apart in a double-blind fashion. The order of administration of hydrocortisone or placebo was counterbalanced between the two groups. The dose of $30 \mathrm{mgs}$ of hydrocortisone was chosen to approximate stress levels of plasma cortisol $1 \frac{1}{2} \mathrm{~h}$ later.

All subjects underwent a positron emission tomography scan and a neuropsychological test battery after the hydrocortisone administration and prior to the trace eyeblink conditioning. Hydrocortisone injection was administered between 0830 and 0900 hours, while trace eye blink conditioning procedure was started between 1430 and 1500 hours. Although the trace conditioning study took place approximately $6 \mathrm{~h}$ after hydrocortisone administration, central effect of glucocorticoids could still be investigated because the genomic effects secondary to the activation of the glucocorticoid receptor occurs over hours to days (Barnes and Adcock, 1993; Reichardt et al, 2000).

\section{Stimulus and Recording Apparatus}

The stimuli and recording were controlled by a commercial system (Contact Precision Instrument). The tone (CS) was a $400-\mathrm{ms}$ duration pure $1 \mathrm{kHz}$ tone at $75 \mathrm{~dB}(\mathrm{~A})$ delivered binaurally through headphones. The puff (US) was a 10-psi air puff (measured at the level of the tank of compressed air) with duration of $50 \mathrm{~ms}$. The air puff was delivered to the left cornea via a $5-\mathrm{ft}$ tubing attached to a special headgear. The eyeblinks were assessed by recording the electromygram (EMG) of the orbicularis occuli with two miniature electrodes placed under the left eye. The ground electrode was placed on the forehead. Electrode impedence was below $5 \mathrm{k} \Omega$. The EMG was filtered $(30-500 \mathrm{~Hz})$ and integrated with a 10 -ms time constant.

\section{Procedure}

Participants were told that they would participate in an experiment in which their reaction to mild air puffs to the eye would be recorded. They were seated in front a TV screen that showed a silent movie during testing. The experimenters fitted each participant with the headgear and the electrodes were attached. Participants were instructed that they would hear tones and that air puff would be delivered to one eye. They were asked to fixate their gaze on the television screen, to blink naturally, and to move as little as possible.

The experimental phase consisted of the delivery of six puff-alone (without tone) trials followed by seven acquisi- 
tion blocks and one extinction block. Each acquisition block started with one tone-alone (not followed by an air puff) followed by nine tone-air puff trials. The extinction block consisted of 10 tone-alone trials. In the tone-puff trials, the puff was administered $900 \mathrm{~ms}$ after the onset of the tone (ie, $500 \mathrm{~ms}$ after the offset of the tone). The interval between trials varied between 10 and $14 \mathrm{~s}$ with a mean of $12 \mathrm{~s}$.

\section{Data Analysis}

Unconditioned EMG blink response magnitudes were scored using the largest EMG peak that occurred 20$100 \mathrm{~ms}$ post puff onset during habituation to the puff. When a blink EMG increased by at least $5 \mu \mathrm{V}$, it was characterized either as a spontaneous blink, an $\alpha$ response, or a conditioned response as determined below.

Blinks in the first $100 \mathrm{~ms}$ after tone onset were classified as $\alpha$ responses. $\alpha$ responses are unconditioned (orienting) responses to the tone (Gormezano, 1966). Several approaches were implemented to analyze CR. One analysis examined CR from $100 \mathrm{~ms}$ after the onset of the tone to the onset of the puff (100-900 ms post-tone onset window). However, one difficulty in analyzing CR in trace eyeblink conditioning experiments is that spontaneous blinks or other nonreflexive blinks can occur in the interval between the onset of the tone and onset of the puff. It is currently not possible to effectively distinguish CR blinks from nonconditioned blinks. Hence, spontaneous blinks need to be assessed and their possible influence on the rate of $\mathrm{CR}$ has to be considered. To minimize the potential impact of spontaneous eyeblink, two types of analyses were conducted. First, the majority of true CRs occur within 300$400 \mathrm{~ms}$ before the onset of the puff (Spence and Ross, 1959). Accordingly, eyeblinks were counted as CR if their onset latency fell in the $400-\mathrm{ms}$ period that preceded the puff (500-900 ms post-tone onset). These CR were considered 'adaptive' because they prevented the air puff from hitting the eye. A second method attempted to account more directly for baseline blinks. This method was modeled after a study by Marenco et al (2003) and implemented in a recent study (Grillon et al, 2004). It consisted of (1) calculating the number of blinks (ie blink onsets) in 14 successive 100 -ms windows starting $500 \mathrm{~ms}$ before the onset of the tone (ending at the onset of the puff), (2) computing the number of spontaneous blinks per 100 -ms window in the $500 \mathrm{~ms}$ that preceded the tone, and (3) subtracting this average blink from each $100-\mathrm{ms}$ window. This provided an assessment of the number of blinks over the entire trial period after taking into account the baseline blink rate in each subject and in each trial. It also allowed us to detect periods of increased blinks relative to the baseline rate of spontaneous blinks.

\section{Statistics}

Since there were no significant differences between patients with PTSD and healthy subjects with respect to age, gender, IQ, smoking history, height, and weight, repeated measures ANOVA without covariates were used for the analysis. The magnitude of the UR/eyeblink during the air puff habituation period was analyzed with a Group (controls, patients) $\times$ Treatment (placebo, hydrocortisol) $\times$ Order (placebo 1st day, hydrocortisone 1st day) $\times$ Trials (1-6) ANOVA. Data during the acquisition and extinction phases were averaged within blocks. The acquisition data were analyzed with a Group (controls, patients) $\times$ Treatment (placebo, hydrocortisol) $\times$ Order (placebo 1st day, hydrocortisone 1st day) $\times$ Block (1-7) ANOVA and the extinction data with a Group (controls, patients) $\times$ Treatment (placebo, hydrocortisol) $\times$ Order (placebo 1st day, hydrocortisone 1st day) ANOVA. Greenhouse-Geisser epsilon corrections were implemented when appropriate to counter violations of the sphericity assumption underlying ANOVA with repeated measures.

\section{RESULTS}

\section{Sociodemographic and Clinical Variables}

Clinical and sociodemographic variables of the 12 PTSD subjects and 12 healthy controls are given in Table 1 . Patients with PTSD were not significantly different from healthy controls, with respect to mean age, IQ, gender distribution, race, height, weight, smoking history, alcohol, and substance use. However, they had significantly higher scores on the CAPS, and significantly higher scores for depression, anxiety, and current and past major depressive disorder (MDD). Comorbid diagnoses included MDD current $(n=4)$, MDD past $(n=3)$, MDD current, and past $(n=1)$, social phobia current $(n=2)$, specific phobia current $(n=2)$, depressive disorder not otherwise specified current and past $(n=1)$, panic disorder current $(n=1)$, generalized anxiety disorder current $(n=1)$, body dysmorphic disorder current $(n=1)$, binge eating disorder past $(n=1)$, bulimia nervosa past $(n=1)$, and alcohol abuse in complete remission $(n=1)$. None of the healthy subjects had a history of present or past psychiatric disorders, with

Table I Sociodemographic Data and Clinical Characteristics in Subjects with PTSD and Healthy Subjects

\begin{tabular}{|c|c|c|c|c|c|}
\hline & $\begin{array}{l}\text { PTSD } \\
(n=12)\end{array}$ & $\begin{array}{l}\text { Healthy } \\
(n=12)\end{array}$ & $t$ & df & $p$ \\
\hline Mean age (years) & $36 \pm 12$ & $36 \pm 11$ & 0.07 & 22 & 0.942 \\
\hline IQ & $116 \pm 9$ & $114 \pm 8$ & -0.63 & 19 & 0.533 \\
\hline CAPS & $81 \pm 21$ & $N A \pm N A$ & & & \\
\hline HAMA & $13 \pm 7$ & $0 \pm 1$ & -5.80 & 19 & 0.000 \\
\hline \multirow[t]{2}{*}{ IDS } & $25 \pm 16$ & $I \pm 1$ & -5.18 & 22 & 0.000 \\
\hline & & & $\chi^{2}$ & df & $p$ \\
\hline Gender: male/female & $2 / 10$ & $4 / 8$ & & & 0.640 \\
\hline $\begin{array}{l}\text { Race (Caucasian/African } \\
\text { American/Other) }\end{array}$ & $7 / 4 / 1$ & $7 / 3 / 2$ & 0.48 & 2 & 0.788 \\
\hline MDD (current) & 5 & 0 & & & 0.037 \\
\hline MDD (past) & 8 & 0 & & & 0.001 \\
\hline $\begin{array}{l}\text { Alcohol dependence/abuse } \\
\text { (past) }\end{array}$ & I & I & & & 1.000 \\
\hline $\begin{array}{l}\text { Substance dependence/abuse } \\
\text { (past) }\end{array}$ & 0 & 0 & & & 1.000 \\
\hline
\end{tabular}


the exception of one healthy male who met criteria for alcohol abuse in remission for 20 years prior to participation in the study. Healthy subjects did not meet criteria for significant trauma exposure in the past. Both healthy controls and PTSD patients were without significant medical illnesses.

Of the subjects with PTSD, three reported childhood physical abuse, three reported childhood sexual abuse, two patients reported both physical and sexual abuse during childhood, one reported witnessing an earthquake during adulthood, and three reported being sexual assaulted in adulthood.

\section{Unconditioned Responses}

The magnitude of the eyeblink (UR) to the air puff during the air puff habituation period did not differ significantly between the PTSD group (mean: $91 \mu \mathrm{V}$, SEM: $16 \mu \mathrm{V}$ ) and the controls (mean: $95 \mu \mathrm{V}$ SEM: $21 \mu \mathrm{V}$ ). The Treatment and the Group $\times$ Treatment interaction were not significant $(\mathrm{F}(1,20)=0.96, \mathrm{~F}(1,20)=1.1$, respectively $)$.

\section{Baseline Eyeblinks (-500 ms - Tone Onset)}

There was no significant difference in the probability of a blink per trial between groups $(\mathrm{F}(1,20)=1.1))$ or treatments $(\mathrm{F}(1,20)=0.16))$ in the $500 \mathrm{~ms}$ that preceded the tone, suggesting similar rates of spontaneous blink in the two groups.

\section{$\alpha$ Responses (Tone Onset $-100 \mathrm{~ms}$ )}

The probability of an alpha response did not differ between groups $(\mathrm{F}(1,20)=0.7))$. It was $7.5 \%(\mathrm{SEM}=2.3 \%)$ and $9.0 \%$ $(\mathrm{SEM}=2.1 \%)$ in the control and PTSD group, respectively. There was a block main effect $(\mathrm{F}(1,20)=6.6, p<0.02)$ due to a reduction of $\alpha$ responses over time (Quadratic trend: $(\mathrm{F}(1,20)=6.9, p<0.01)$. Alpha responses were not affected by the drug treatment $(\mathrm{F}(1,20)=0.02)$. There was no significant Drug $\times$ Group interaction.

\section{Conditioned Responses (100-900 ms Post-Tone Onset)}

The mean CR over the entire tone onset-puff onset interval (excluding the $0-100 \mathrm{~ms}$ alpha period) is shown in Figure 1. While the two treatments had similar effect on CR in the control group, CR performance was considerably reduced by hydrocortisone in the PTSD group. This resulted in both a Treatment main effect $(\mathrm{F}(1,20)=5.1, p<0.04)$ and a Group $\times$ Treatment interaction $(\mathrm{F}(1,20)=4.1, p<0.04)$. Focused contrasts within groups confirmed that hydrocortisone reduced the percent $\mathrm{CR}$ in the PTSD group $(\mathrm{F}(1,20)=10.2, \quad p<0.004)$, but not in the control $(\mathrm{F}(1,20)=0.006)$. Further, percent $\mathrm{CR}$ in the placebo condition did not significantly differ between the two groups $(F(1,20)=0.8)$. No other effect reached significance.

\section{Adaptive CR (500-900 ms Post-Tone Onset)}

Figure 2 shows the percent adaptive CR averaged within each block. Very similar results were obtained with the adaptive CR as for the CR in the $100-900 \mathrm{~ms}$ range. There was a significant Group $\times$ Treatment effect $(F(1,20)=11.6$, $p<0.0003$ ). Contrasts within groups confirmed that hydrocortisone reduced the percent $\mathrm{CR}$ in the PTSD group $(\mathrm{F}(1,20)=12.9, p<0.002)$, but not in the control $(\mathrm{F}(1,20)=$ 1.7). Percent $C R$ in the placebo condition did not significantly differ between the two groups $(F(1,20)=0.8)$. No other effect reached significance.

Figure 2 also shows that there was a significant reduction in percent $\mathrm{CR}$ when the tone was no longer followed by the puff in the extinction block. A three-way ANOVA, Group (Control, PTSD) $\times$ Treatment (placebo, hydrocortisone) $\times$ Extinction (last acquisition block, extinction block) revealed a significant Extinction main effect $(\mathrm{F}(1,20)=$ 25.1, $p<0.0009)$ and a Group $\times$ Extinction interaction $(\mathrm{F}(1,20)=5.6, p<0.03)$, reflecting greater extinction (ie reduction in the number of $\mathrm{CR}$ in the extinction phase) in the patients compared to the control group.

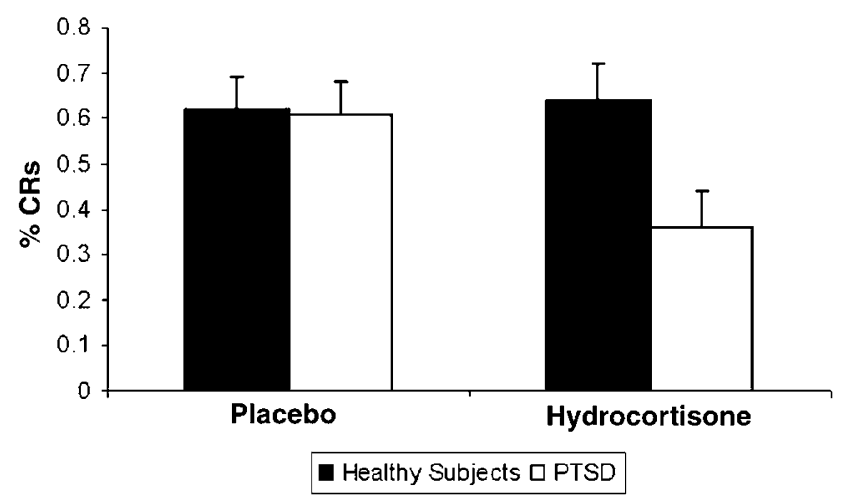

Figure I Mean conditioned response (CR) averaged over the seven acquisition blocks in the patients with PTSD and the healthy controls. CRs were identified in the 100-900 ms post-tone window.
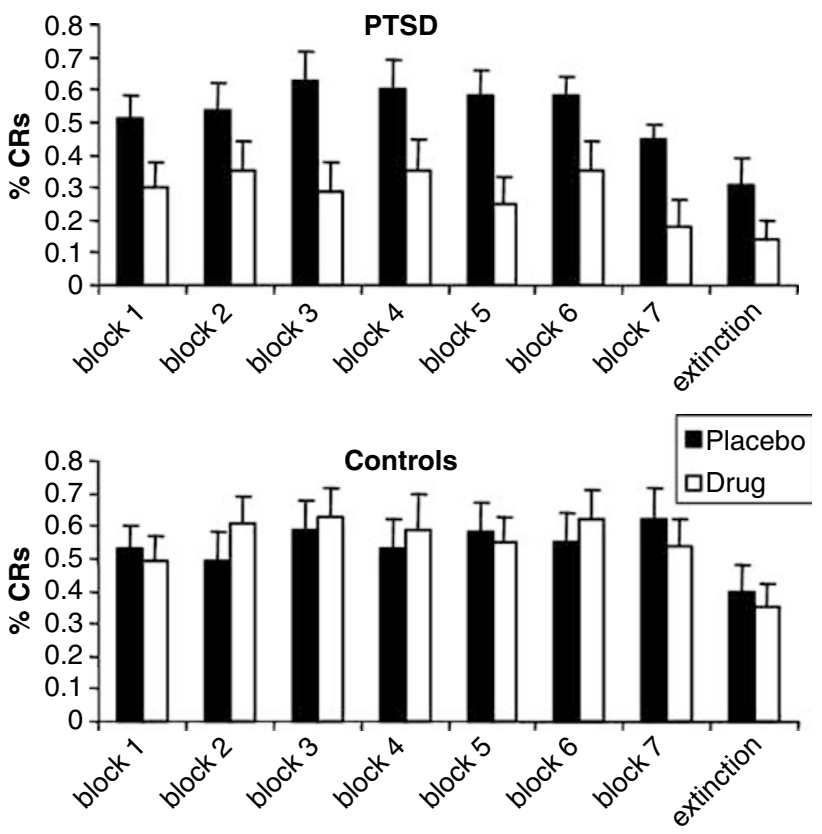

Figure 2 Adaptive CR in the 500-900 ms post-tone window during the seven acquisition blocks and during one extinction block in the patients with PTSD and the healthy controls. 
When the patient sample was subdivided into those with PTSD and MDD $(n=5)$ and PTSD without MDD $(n=7)$, only subjects with PTSD without MDD tended to be more sensitive to the effects of hydrocortisone compared to healthy controls $(\mathrm{F}=3.71, \mathrm{df}=1,1 ; p=0.08)$.

\section{Contribution of Spontaneous Blinks to CR}

Figure 3 shows the analysis based on successive 100-ms windows starting $500 \mathrm{~ms}$ before the tone. Each bar represents the rate of blink in a 100 -ms period averaged over the 70 trials minus the average blink in the $500-\mathrm{ms}$ period that preceded the tone. Analyses in the nonadaptive region $(100-500 \mathrm{~ms}$ post-tone) revealed no significant Group effect $(\mathrm{F}(1,20)=0.04)$ or Group $\times$ treatment interaction $(\mathrm{F}(1,20)=2.5)$. Analyses in the adaptive $\mathrm{CR}$ region (500-900 ms post-tone) revealed a significant Group main effect $(\mathrm{F}(1,20)=7.8, p<0.01)$ and a Group $\times$ Treatment interaction $(\mathrm{F}(1,20)=7.4, p<0.01)$. The Group $\times$ Treatment interaction confirms that hydrocortisone reduced the adaptive CR in the PTSD group, but not in the control group.

\section{Plasma Cortisol and ACTH Levels}

Plasma cortisol levels 1.5 following hydrocortisone administration were $31.20 \pm 3.88 \mu \mathrm{g} / \mathrm{dl}$ in healthy subjects and $22.25 \pm 4.07 \mu \mathrm{g} / \mathrm{dl}$ in patients with PTSD (group: $\mathrm{F}=2.87$, $\mathrm{df}=1,18.4, p=0.11$; drug: $\mathrm{F}=72.18, \mathrm{df}=1,16.9, p<0.001$; group $\times$ drug: $\mathrm{F}=1.83, \mathrm{df}=1,16.9, p=0.19$ ), which approx-

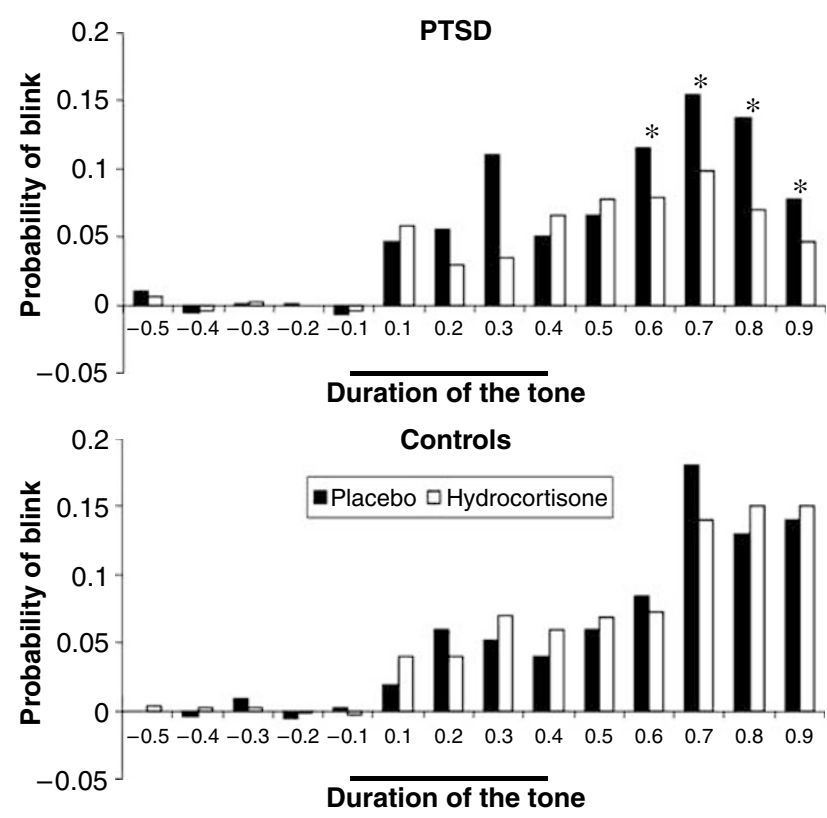

Figure 3 Frequency of eyeblinks in successive 100-ms windows of analysis starting $500 \mathrm{~ms}$ before TONE onset over the 60 acquisition trials in the patients and the controls. The $y$-axis shows the percent eyeblinks for each window minus the mean frequency of eyeblinks averaged over the 500-ms pre-TONE period so as to correct for the potential effect of spontaneous eyeblinks. The black horizontal line under the $x$-axis represents the time when the TONE was present. * Indicates a significant treatment effect in the PTSD group $(p<0.05)$. imate stress levels of cortisol as reported in previous studies (Howard et al, 1955; Morgan et al, 2000, 2001). The corresponding plasma ACTH values were $6.71 \pm 1.01 \mathrm{pl} / \mathrm{ml}$ in healthy subjects and $4.84 \pm 1.10 \mathrm{pl} / \mathrm{ml}$ for patients with PTSD (group: $\mathrm{F}=0.21, \mathrm{df}=1,21.1, p=0.65$; drug: $\mathrm{F}=27.06$, $\mathrm{df}=1,21.2, p<0.001$; group $\times$ drug: $\mathrm{F}=2.32, \mathrm{df}=1,21.2$, $p=0.14$ ). Plasma cortisol levels prior to trace eye blink conditioning were $29.16 \pm 3.70 \mu \mathrm{g} / \mathrm{dl}$ in healthy subjects and $13.97 \pm 3.90 \mu \mathrm{g} / \mathrm{dl}$ in patients with PTSD (group: $\mathrm{F}=9.28$, $\mathrm{df}=1,17.4, p=0.007$; drug: $\mathrm{F}=31.49, \mathrm{df}=1,17.1, p<0.001$; group $\times$ drug: $\mathrm{F}=5.93, \mathrm{df}=1,17.1, p=0.03)$. The corresponding plasma ACTH values were $3.42 \pm 0.54 \mathrm{pl} / \mathrm{ml}$ in healthy subjects and $3.99 \pm 0.55 \mathrm{pl} / \mathrm{ml}$ in patients with PTSD (group: $\mathrm{F}=1.80, \mathrm{df}=1,20.8, \quad p=0.22 ;$ drug: $\mathrm{F}=49.28$, $\mathrm{df}=1,19.4, p<0.001 ;$ group $\times$ drug: $\mathrm{F}=1.62, \mathrm{df}=1,19.4$, $p=0.22$ ). Plasma cortisol and plasma ACTH levels $1.5 \mathrm{~h}$ following hydrocortisone administration and prior to the trace eye blink conditioning procedure were not correlated with conditioned response.

\section{DISCUSSION}

Using the trace eyeblink paradigm, we found that mean conditioned response on placebo was similar in patients with PTSD and healthy controls. Hydrocortisone administration decreased the mean number of conditioned responses and the number of adaptive conditioned responses in PTSD but not in healthy controls, suggesting increased glucocorticoid sensitivity only in PTSD patients. Since rates of baseline eyeblink and $\alpha$ responses to tone following hydrocortisone and placebo administration were similar in PTSD subjects and healthy controls, the effects of glucocorticoids were specific to associative learning in PTSD and do not reflect enhanced spontaneous blink rate in the PTSD group.

The lack of differences in \% conditioned response and adaptive conditioned response in patients with PTSD and healthy subjects under placebo conditions suggests that the type of associative learning measured by eyeblink trace conditioning was not impaired at baseline in PTSD. Since preclinical studies support the role for $\mathrm{CA} 3$ and $\mathrm{CA} 1$ hippocampal neurons in mediating eyeblink trace conditioning (Berger and Thompson, 1978; Clark and Squire, 1998; Moyer et al, 1990; Solomon et al, 1986; Weiss et al, 1996), the present data are similar to some studies demonstrating normal hippocampal-mediated neuropsychological function in PTSD (Neylan et al, 2004; Pederson et al, 2004; Vasterling et al, 1998).

Since hydrocortisone impaired associative learning only in patients with PTSD, the present data support the possibility that PTSD is associated with greater central sensitivity to glucocorticoids. Although the findings from the current study is similar to several previous reports that have demonstrated increased glucocorticoid sensitivity in PTSD (Goenjian et al, 1996; Stein et al, 1997b; Yehuda et al, $1995,2004 \mathrm{~b}, 1993)$, this is the first study to evaluate glucocorticoid sensitivity of the brain structures mediating trace eyeblink conditioning. Previous studies that evaluated glucocorticoid sensitivity in PTSD investigated changes in peripheral measures such as salivary cortisol (Goenjian et al, 1996), lymphocytes (Yehuda et al, 1995), mononuclear 
leukocytes (Yehuda et al, 2004a), plasma immune measures (Rohleder et al, 2004) and dermal vasoconstriction response in the forearm (Coupland et al, 2003). The result from the present study contrasts a recent report demonstrating that patients with PTSD had decreased sensitivity to dexamethasone-mediated impairment of declarative memory (Bremner et al, 2004). The conflicting results may be attributed to the possibility that the two tests assay different aspects of hippocampal function. The Wechsler memory scale evaluates declarative memory, while trace eyeblink conditioning evaluates associative learning.

Since patients with PTSD and not healthy subjects had a significant decrease in conditioned response following hydrocortisone, it is likely that the areas mediating trace eyeblink conditioning are more sensitive to glucocorticoids in PTSD. Increased sensitivity of the trace eyeblink conditioning task to hydrocortisone could reflect increased sensitivity of glucocorticoid receptors in the hippocampus in PTSD. An extensive body of preclinical work confirms that glucose transport is inhibited following hydrocortisone administration. A more immediate effect is mediated through rapid membrane effects (Falkenstein et al, 2000; McEwen, 1997; Trueba et al, 1989), while a delayed action $(4-12 \mathrm{~h})$ is mediated through the glucocorticoid receptor (Horner et al, 1990; Munck, 1971; Virgin et al, 1991). Since the main goal of the study was to evaluate the sensitivity of the glucocorticoid receptors in PTSD, a longer time delay between administration of hydrocortisone and trace eye blink conditioning was chosen. However, the hypothesis that hydrocortisone-mediated impairment in trace eyeblink conditioning is a surrogate marker for central glucocorticoid receptor function needs confirmation by translational studies using selective agonists and antagonist of the glucocorticoid receptor.

Acute administration of glucocorticoids facilitates eyeblink conditioning in male rats in contrast to female rats (Wood et al, 2001; Wood and Shors, 1998). Since there were no differences in gender distribution between PTSD and healthy subjects, it is likely that PTSD rather than gender contributed to the differences in associative learning following hydrocortisone administration. Since plasma cortisol levels prior to the trace eyeblink procedure were not correlated with conditioned response, it is possible that an acute elevation of cortisol in subjects with PTSD results in a persistent impairment in associative learning.

Limitations of the study include the possibility that increased glucocorticoid sensitivity in the cerebellum could explain the findings in the present study (Christian and Thompson, 2003), the inability to evaluate the role of gender given the small number of men enrolled, and the lack of behavioral effect of hydrocortisone on healthy subjects. Since plasma cortisol measures were not obtained $24 \mathrm{~h}$ prior to the eyeblink conditioning procedure, it is unclear if the significant difference in plasma cortisol levels between patients with PTSD and healthy subjects is due to differences in baseline cortisol levels, or due to pharmacokinetic differences in hydrocortisone metabolism.

In conclusion, subjects with PTSD had normal conditioned response to a trace eye blink conditioning paradigm, suggesting normal associative learning in this disorder. Using this paradigm, we were able to demonstrate an increased sensitivity in a hippocampal-dependant task to glucocorticoids in PTSD. Longitudinal trace eyeblink conditioning studies in trauma-exposed subjects within and without PTSD may help determine if hippocampal dysfunction is a risk factor or a consequence of PTSD or hypocortesolemia. Positron emission tomography receptor studies using ligands that specifically target central glucocorticoid receptors could shed light into the pathophysiology of this disorder and perhaps lead to better treatments.

\section{ACKNOWLEDGEMENTS}

We thank Ellen Polignano, RN, Tracy Waldeck, PhD, and Rajni Agarwal, MA for help with conducting the study, Kathy West for the plasma cortisol assays, and Alex Noury MA for assistance with the manuscript.

\section{REFERENCES}

Ayers ED, White J, Powell DA (2003). Pavlovian eyeblink conditioning in combat veterans with and without posttraumatic stress disorder. Integr Physiol Behav Sci 38: 230-247.

Barnes PJ, Adcock I (1993). Anti-inflammatory actions of steroids: molecular mechanisms. Trends Pharmacol Sci 14: 436-441.

Berger TW, Thompson RF (1978). Neuronal plasticity in the limbic system during classical conditioning of the rabbit nictitating membrane response. I. The hippocampus. Brain Res 145: 323-346.

Beylin AV, Gandhi CC, Wood GE, Talk AC, Matzel LD, Shors TJ (2001). The role of the hippocampus in trace conditioning: temporal discontinuity or task difficulty? Neurobiol Learn Mem 76: 447-461.

Beylin AV, Shors TJ (2003). Glucocorticoids are necessary for enhancing the acquisition of associative memories after acute stressful experience. Horm Behav 43: 124-131.

Blake DD, Weathers FW, Nagy LM, Kaloupek DG, Gusman FD, Charney DS et al (1995). The development of a ClinicianAdministered PTSD Scale. J Trauma Stress 8: 75-90.

Blake DD, Weathers FW, Nagy LM, Kaloupek DG, Kiaumnizer G, Charney DS et al (1990). A clinician rating scale for assessing current and lifetime PTSD: the CAPS-1. The Behav Therapist 13: $187-188$.

Bremner JD, Vermetten E, Mazure CM (2000). Development and preliminary psychometric properties of an instrument for the measurement of childhood trauma: the early trauma inventory. Depress Anxiety 12: 1-12.

Bremner JD, Vythilingam M, Vermetten E, Afzal N, Nazeer A, Newcomer JW et al (2004). Effects of dexamethasone on declarative memory function in posttraumatic stress disorder. Psychiatry Res 129: 1-10.

Christian KM, Thompson RF (2003). Neural substrates of eyeblink conditioning: acquisition and retention. Learn Mem 10: 427-455.

Clark RE, Squire LR (1998). Classical conditioning and brain systems: the role of awareness. Science 280: 77-81.

Coupland NJ, Hegadoren KM, Myrholm J (2003). Increased beclomethasone-induced vasoconstriction in women with posttraumatic stress disorder. J Psychiatr Res 37: 221-228.

Falkenstein E, Tillmann HC, Christ M, Feuring M, Wehling M (2000). Multiple actions of steroid hormones - a focus on rapid, nongenomic effects. Pharmacol Rev 52: 513-556.

First M, Spitzer R, Gibbon M, Williams J (1997). Structured Clinical Interview for DSM-IV. American Psychiatric Press: Washington, DC. 
Fortier CB, Disterhoft JF, Capozzi S, Kilduff P, Cronin-Golomb A, McGlinchey RE (2003). Conditional discrimination learning in patients with bilateral medial temporal lobe amnesia. Behav Neurosci 117: 1181-1195.

Goenjian AK, Yehuda R, Pynoos RS, Steinberg AM, Tashjian M, Yang RK et al (1996). Basal cortisol, dexamethasone suppression of cortisol, and MHPG in adolescents after the 1988 earthquake in Armenia. Am J Psychiatry 153: 929-934.

Gormezano I (1966). Classical conditioning. In: Sidowski J (ed). Experimental Methods and Instrumentation in Psychology. McGraw-Hill: New York. pp 385-420.

Gotovac K, Sabioncello A, Rabatic S, Berki T, Dekaris D (2003). Flow cytometric determination of glucocorticoid receptor (GCR) expression in lymphocyte subpopulations: lower quantity of GCR in patients with post-traumatic stress disorder (PTSD). Clin Exp Immunol 131: 335-339.

Grillon C, Smith K, Haynos A, Nieman LK (2004). Deficits in hippocampus-mediated Pavlovian conditioning in endogenous hypercortisolism. Biol Psychiatry 56: 837-843.

Horner HC, Packan DR, Sapolsky RM (1990). Glucocorticoids inhibit glucose transport in cultured hippocampal neurons and glia. Neuroendocrinology 52: 57-64.

Howard JM, Olney JM, Frawley J (1955). Studies of adrenal function in combat and wounded soldiers. Annal Surg 141: 314-320.

Lavond DG, Kim JJ, Thompson RF (1993). Mammalian brain substrates of aversive classical conditioning. Annu Rev Psychol 44: 317-342.

Marenco S, Weinberger DR, Schreurs BG (2003). Single-cue delay and trace classical conditioning in schizophrenia. Biol Psychiatry 53: 390-402.

McEchron MD, Disterhoft JF (1997). Sequence of single neuron changes in CA1 hippocampus of rabbits during acquisition of trace eyeblink conditioned responses. J Neurophysiol 78: 1030-1044.

McEwen BS (1997). The brain is an important target of adrenal steroid actions. A comparison of synthetic and natural steroids. Ann NY Acad Sci 823: 201-213.

Morgan III CA, Wang S, Mason J, Southwick SM, Fox P, Hazlett G et al (2000). Hormone profiles in humans experiencing military survival training. Biol Psychiatry 47: 891-901.

Morgan III CA, Wang S, Rasmusson A, Hazlett G, Anderson G, Charney DS (2001). Relationship among plasma cortisol, catecholamines, neuropeptide $\mathrm{Y}$, and human performance during exposure to uncontrollable stress. Psychosom Med 63: 412-422.

Moyer Jr JR, Deyo RA, Disterhoft JF (1990). Hippocampectomy disrupts trace eye-blink conditioning in rabbits. Behav Neurosci 104: 243-252.

Munck A (1971). Glucocorticoid inhibition of glucose uptake by peripheral tissues: old and new evidence, molecular mechanisms, and physiological significance. Perspect Biol Med 14: 265-269.

Neylan TC, Lenoci M, Rothlind J, Metzler TJ, Schuff N, Du AT et al (2004). Attention, learning, and memory in posttraumatic stress disorder. J Trauma Stress 17: 41-46.

Pederson CL, Maurer SH, Kaminski PL, Zander KA, Peters CM, Stokes-Crowe LA et al (2004). Hippocampal volume and memory performance in a community-based sample of women with posttraumatic stress disorder secondary to child abuse. J Trauma Stress 17: 37-40.

Reichardt HM, Tronche F, Berger S, Kellendonk C, Schutz G (2000). New insights into glucocorticoid and mineralocorticoid signaling: lessons from gene targeting. Adv Pharmacol 47: 1-21.
Rohleder N, Joksimovic L, Wolf JM, Kirschbaum C (2004). Hypocortisolism and increased glucocorticoid sensitivity of pro-inflammatory cytokine production in Bosnian war refugees with posttraumatic stress disorder. Biol Psychiatry 55: 745-751.

Solomon PR, Vander Schaaf ER, Thompson RF, Weisz DJ (1986). Hippocampus and trace conditioning of the rabbit's classically conditioned nictitating membrane response. Behav Neurosci 100: $729-744$.

Spence KW, Ross LE (1959). A methodological study of the form and latency of eyelid responses in conditioning. J Exp Psychol 58: $376-381$.

Stein MB, Yehuda R, Koverola C, Hanna C (1997b). Enhanced dexamethasone suppression of plasma cortisol in adult women traumatized by childhood sexual abuse. Biol Psychiatry 42: $680-686$.

Steinmetz JE, Tracy JA, Green JT (2001). Classical eyeblink conditioning: clinical models and applications. Integr Physiol Behav Sci 36: 220-238.

Trueba M, Vallejo AI, Rodriguez I, Ibarrola I, Sancho MJ, Marino A et al (1989). Evidence for the presence of specific binding sites for corticoids in mouse liver plasma membranes. J Membr Biol 108: $115-124$.

Vasterling JJ, Brailey K, Constans JI, Sutker PB (1998). Attention and memory dysfunction in posttraumatic stress disorder. Neuropsychology 12: 125-133.

Virgin Jr CE, Ha TP, Packan DR, Tombaugh GC, Yang SH, Horner HC et al (1991). Glucocorticoids inhibit glucose transport and glutamate uptake in hippocampal astrocytes: implications for glucocorticoid neurotoxicity. J Neurochem 57: 1422-1428.

Weiss C, Kronforst-Collins MA, Disterhoft JF (1996). Activity of hippocampal pyramidal neurons during trace eyeblink conditioning. Hippocampus 6: 192-209.

Wood GE, Beylin AV, Shors TJ (2001). The contribution of adrenal and reproductive hormones to the opposing effects of stress on trace conditioning in males versus females. Behav Neurosci 115: 175-187.

Wood GE, Shors TJ (1998). Stress facilitates classical conditioning in males, but impairs classical conditioning in females through activational effects of ovarian hormones. Proc Natl Acad Sci USA 95: 4066-4071.

Yehuda R, Boisoneau D, Lowy MT, Giller Jr EL (1995). Doseresponse changes in plasma cortisol and lymphocyte glucocorticoid receptors following dexamethasone administration in combat veterans with and without posttraumatic stress disorder. Arch Gen Psychiatry 52: 583-593.

Yehuda R, Golier JA, Yang RK, Tischler L (2004a). Enhanced sensitivity to glucocorticoids in peripheral mononuclear leukocytes in posttraumatic stress disorder. Biol Psychiatry 55: $1110-1116$.

Yehuda R, Halligan SL, Golier JA, Grossman R, Bierer LM (2004b). Effects of trauma exposure on the cortisol response to dexamethasone administration in PTSD and major depressive disorder. Psychoneuroendocrinology 29: 389-404.

Yehuda R, Southwick SM, Krystal JH, Bremner D, Charney DS, Mason JW (1993). Enhanced suppression of cortisol following dexamethasone administration in posttraumatic stress disorder. Am J Psychiatry 150: 83-86.

Yehuda R, Teicher MH, Trestman RL, Levengood RA, Siever LJ (1996). Cortisol regulation in posttraumatic stress disorder and major depression: a chronobiological analysis. Biol Psychiatry 40: $79-88$. 